\title{
Associations of immunological factors with metabolic syndrome and its characteristic elements in Chinese centenarians
}

Shihui $\mathrm{Fu}^{1,2+}$, Yao Yao ${ }^{3,4+}$, Faqin Lv ${ }^{5}$, Fu Zhang ${ }^{6}$, Yali Zhao ${ }^{6 *}$ and Fuxin Luan ${ }^{6^{*}}$

\begin{abstract}
Background: Metabolic syndrome (MetS) has an increased prevalence (approximately 20-25\% of the adult population) all over the world. Immunological function is significantly associated with the development of MetS, and MetS is beginning to be considered as a chronic immune-related disease. The present study addressed on the associations of immunological factors with MetS and its characteristic elements in Chinese centenarians.

Methods: Hainan is a longevity region with the highest population density of centenarians in China. The China Hainan Centenarian Cohort Study has a considerable sample size, and provides a significant population-based sample of centenarians. Home interview, physical examination and blood analysis were conducted following standard procedures.

Results: All centenarians had a median age of 102 (100-115) years, and the proportion of females was $80.8 \%$. The proportion of centenarians with MetS was 16.0\% (135 centenarians). Abdominal obesity, hypertension, dyslipidemia and diabetes mellitus had a prevalence of $26.4 \%$ (223 centenarians), $73.7 \%$ (623 centenarians), 40.4\% (341 centenarians) and 10.7\% (90 centenarians), respectively. In Logistic regression analyses, MetS was significantly associated with immunoglobulin $\mathrm{E}$ and complement $\mathrm{C} 3$ levels $(\mathrm{P}<0.05$ for all). Abdominal obesity was significantly associated with immunoglobulin $\mathrm{E}$ and complement $\mathrm{C} 3$ levels $(\mathrm{P}<0.05$ for all).

Conclusions: The present study provides epidemiological evidence that MetS has significant associations with immunoglobulin E and complement C3 levels, and demonstrates that abdominal obesity is significantly associated with immunoglobulin E and complement C3 levels in Chinese centenarians.
\end{abstract}

Keywords: Abdominal obesity, Chinese centenarians, Complement C3, Immunoglobulin E, Metabolic syndrome

\section{Background}

Metabolic syndrome (MetS) has an increased prevalence (approximately $20-25 \%$ of the adult population) all over the world $[1,2]$. MetS is a risk factor for the development of cardiovascular disorders, and results in an increased risk of cardiovascular events and all-cause mortality [3, 4]. Characteristic elements of MetS include abdominal obesity, high blood pressure, high blood glucose and abnormal blood lipids, all of which are risk factors for

\footnotetext{
*Correspondence: zhaoyl301@163.com; baisui301@163.com

'Shihui Fu and Yao Yao are co-first authors

${ }^{6}$ Central Laboratory, Hainan Branch of Chinese People's Liberation Army

General Hospital, Sanya, China

Full list of author information is available at the end of the article
}

cardiovascular disorders and mortality [5]. Immunological function is significantly associated with the development of MetS, and MetS is beginning to be considered as a chronic immune-related disease [6]. It has been suggested that elevated immunological factors, such as immunoglobulin A, E, G, M, kappa and lambda, and complement $\mathrm{C} 3$ and $\mathrm{C} 4$, correlate with cardiovascular mortality [7]. Regarding the associations of immunological factors with MetS and its characteristic elements, scarce studies have been performed and obtained contradicting results, making further epidemiological investigations necessary [3, 8-10].

The prevalence of MetS increases with age, approaching $42.0 \%$ in US adults aged 70 years or more [11]. 
Epidemiological studies of MetS in the elderly, particularly in the centenarians, are therefore of great value. The centenarians have been suggested to have a delayed or escaped onset and interaction of age-related abnormalities [12]. Some centenarians may experience a delayed onset of age-related abnormalities (delayers), while others may do not succumb to any age-related abnormalities (escapers) [13]. Thus, the centenarians may represent a prototype of successful aging [14]. However, it is still under scientific debate [15]. More importantly, what is this model of successful aging? Studies analyzing this model in the centenarians could provide valuable information for early promoting successful aging and preventing age-related abnormalities. As a possible part of this model, whether the interaction between MetS and immunological factors exists in the aging process of centenarians is still unclear and needs further studies.

Although the associations of immunological factors with MetS and its characteristic elements have already been explored in previous studies, they have not been done in the centenarians, particularly in Chinese centenarians, in a large-scale study $[8,9]$. Consequently, there is a need to carry out the investigations in Chinese centenarians. Hainan is a longevity region with the highest population density of centenarians in China. The China Hainan Centenarian Cohort Study (CHCCS) has a considerable sample size, and provides a significant population-based sample of Chinese centenarians. The present study addressed on the associations of immunological factors with MetS and its characteristic elements in Chinese centenarians.

\section{Methods}

\section{Study population}

The CHCCS involves a population-based cohort of individuals aged 100 years or more recruited between July 2014 and December 2016 in 18 cities and counties of Hainan Province, China. Its cohort profile has been described previously [16]. Sample size (1002 centenarians) was determined by the National Civil Registry and provided by the Hainan Civil Affairs Bureau. Age was consistent with national identification cards. The final analysis had 845 centenarians with complete data. All these centenarians had no diagnosed rheumatoid arthritis and other autoimmune diseases.

\section{Standard procedures}

Home interview, physical examination and blood analysis were conducted following standard procedures by the same research team and central laboratory of the Hainan Branch of Chinese People's Liberation Army General Hospital [17]. The research team included internists, geriatricians, cardiologists, endocrinologists, nephrologists and nurses. Based on the recommendations by the World Health Organization, waist circumference (WC) was measured twice using the tapes at the midpoint between the last rib and the iliac crest [18]. Systolic and diastolic blood pressures (SBP and DBP) were measured in the right arm of seated centenarians. Samples of venous blood were extracted from the centenarians and transported within $4 \mathrm{~h}$ in chilled bio-transport containers $\left(4^{\circ} \mathrm{C}\right)$ to our central laboratory. Serum levels of immunoglobulins and complements were measured with a fully automatic protein analyzer (BNII; Siemens AG, Munich, Germany; CV within group: $1.4-4.7 \%$; CV between groups: $2.5-5.5 \%)$. Serum levels of triglyceride, high-density lipoprotein cholesterol (HDL-C) and fasting blood glucose (FBG) were measured by enzymatic assays (Roche Products Ltd, Basel, Switzerland) with a fully automatic biochemical autoanalyzer (Cobas c702; Roche Products Ltd, Basel, Switzerland; CV within group: 0.52.3\%; CV between groups: $0.8-3.1 \%$ ) and low-density lipoprotein cholesterol (LDL-c) was calculated. All assays were conducted by qualified technicians without knowledge of the clinical data.

\section{Variable definitions}

According to the worldwide consensus on the definition of MetS established by the International Diabetes Federation, the centenarians were considered to have MetS if they had abdominal obesity and at least two of the following factors were satisfied: high blood pressure $(\mathrm{SBP} \geq 130 \mathrm{mmHg}$ or $\mathrm{DBP} \geq 85 \mathrm{mmHg}$ or previously diagnosed hypertension), high blood glucose $(\mathrm{FBG} \geq 5.6 \mathrm{mmol} / \mathrm{L}$ or previously diagnosed diabetes mellitus), and abnormal blood lipids (triglyceride $\geq 1.7 \mathrm{mmol} / \mathrm{L}$ or $\mathrm{HDL}-\mathrm{C}<1.0 \mathrm{mmol} / \mathrm{L}$ in males and $<1.3 \mathrm{mmol} / \mathrm{L}$ in females or previously diagnosed dyslipidemia) [19]. Based on Chinese guidelines on the prevention and control of obesity, the presence of abdominal obesity was established when $W C \geq 85 \mathrm{~cm}$ for men and $\geq 80 \mathrm{~cm}$ for women [20]. Hypertension was defined as $\mathrm{SBP} \geq 140 \mathrm{mmHg}, \mathrm{DBP} \geq 90 \mathrm{mmHg}$ or using anti-hypertensive drugs [21]. Diabetes mellitus was defined as $\mathrm{FBG} \geq 7.0 \mathrm{mmol} / \mathrm{L}$ or using antidiabetic drugs/insulin [22]. Dyslipidemia was defined as triglyceride $\geq 1.7 \mathrm{mmol} / \mathrm{L}, \quad \mathrm{LDL}-\mathrm{C} \geq 3.37 \mathrm{mmol} / \mathrm{L}$, HDL-C $\geq 1.04 \mathrm{mmol} / \mathrm{L}$ or using lipid-regulating drugs [23].

\section{Statistical analyses}

Continuous variables with a normal distribution were presented as mean \pm standard deviation, and then compared with a Student's t-test. Continuous variables with a skewed distribution were presented as median (interquartile range), and then compared with a Mann-Whitney U-test. Categorical variables were 
presented as number (percentage), and then compared with a Chi square test. Logistic regression models were carried out with and without the adjustment of age and sex to assess the associations of immunological factors with MetS and its characteristic elements. MetS, its characteristic elements including abdominal obesity, high blood pressure, high blood glucose and abnormal blood lipids, and different morbidities including hypertension, diabetes mellitus and dyslipidemia were used as dependent variables in these models. Immunological factors, such as immunoglobulin A, E, G, M, kappa and lambda, and complement $\mathrm{C} 3$ and $\mathrm{C} 4$, were used as independent variables in these models. Statistical significance was assessed using 2-tailed $\mathrm{p}$ values at a threshold of 0.05. Statistical analyses were carried out using SPSS version 17 (SPSS Inc., Chicago, IL, US).

\section{Results}

All centenarians had a median age of 102 (100$115)$ years, and the proportion of females was $80.8 \%$. The proportion of centenarians with MetS was 16.0\% (135 centenarians). Abdominal obesity, hypertension, dyslipidemia and diabetes mellitus had a prevalence of $26.4 \%$ (223 centenarians), 73.7\% (623 centenarians), 40.4\% (341 centenarians) and $10.7 \%$ (90 centenarians), respectively. Table 1 provides the features of all centenarians with and without MetS. There were more females, higher prevalence of abdominal obesity, hypertension, dyslipidemia and diabetes mellitus, higher levels of WC, SBP, DBP, triglyceride and LDL-C, and lower levels of HDL-C in the centenarians with MetS than those without MetS $(\mathrm{P}<0.05$ for all). Meanwhile, the centenarians with MetS had lower levels of immunoglobulin $\mathrm{E}$ and higher levels of complement $\mathrm{C} 3$ than those without MetS $(\mathrm{P}<0.05$ for all; Fig. 1).

In Logistic regression analyses (Table 2), MetS was significantly associated with immunoglobulin $\mathrm{E}$ \{crude odds ratio (OR) [95\% confidence interval (95\% CI)] 0.980 (0.964-0.996); adjusted OR (95\% CI) 0.981 (0.966-0.997); $\mathrm{P}<0.05$ for all $\}$ and complement $\mathrm{C} 3$ levels [crude OR (95\% CI) 1.022 (1.013-1.030); adjusted OR (95\% CI) 1.020 (1.012-1.029); $\mathrm{P}<0.05$ for all]. As shown in Table 3,

Table 1 Features of all centenarians with and without MetS

\begin{tabular}{|c|c|c|c|c|}
\hline Features & All & Non-MetS $(n=710)$ & MetS $(n=135)$ & P value \\
\hline Age $(\text { years })^{\mathrm{a}}$ & $102(101-104)$ & $102(101-104)$ & $102(101-104)$ & 0.268 \\
\hline Females $(\%)^{b}$ & $683(80.8)$ & $558(78.6)$ & $125(92.6)$ & $<0.001$ \\
\hline Abdominal obesity $(\%)^{\mathrm{b}}$ & $223(26.4)$ & $88(12.4)$ & $135(100.0)$ & $<0.001$ \\
\hline Hypertension (\%) ${ }^{\mathrm{b}}$ & $623(73.7)$ & $508(71.5)$ & $115(85.2)$ & 0.001 \\
\hline High blood pressure (\%) & $712(84.3)$ & $586(82.5)$ & $126(93.3)$ & 0.002 \\
\hline Dyslipidemia $(\%)^{b}$ & $341(40.4)$ & $248(34.9)$ & $93(68.9)$ & $<0.001$ \\
\hline Abnormal blood lipids (\%) ${ }^{b}$ & $317(37.5)$ & $212(29.9)$ & $105(77.8)$ & $<0.001$ \\
\hline Diabetes mellitus (\%) ${ }^{\mathrm{b}}$ & $90(10.7)$ & $59(8.3)$ & $31(23.0)$ & $<0.001$ \\
\hline High blood glucose $(\%)^{b}$ & $247(29.2)$ & $172(24.2)$ & 75 (55.6) & $<0.001$ \\
\hline$W C(\mathrm{~cm})^{\mathrm{a}}$ & $75(70-81)$ & $74(68-78)$ & $85(82-90)$ & $<0.001$ \\
\hline $\mathrm{SBP}(\mathrm{mmHg})^{\mathrm{a}}$ & $150(136-170)$ & $148(133-168)$ & $158(145-179)$ & $<0.001$ \\
\hline $\mathrm{DBP}(\mathrm{mmHg})^{\mathrm{a}}$ & $76(67-83)$ & $75(66-83)$ & $78(72-86)$ & 0.002 \\
\hline Triglyceride $(\mathrm{mmol} / \mathrm{L})^{\mathrm{a}}$ & $1.03(0.80-1.41)$ & $0.98(0.77-1.30)$ & $1.57(1.02-1.90)$ & $<0.001$ \\
\hline $\mathrm{HDL}-\mathrm{C}(\mathrm{mmol} / \mathrm{L})^{\mathrm{a}}$ & $1.40(1.17-1.67)$ & $1.43(1.21-1.71)$ & $1.22(1.02-1.45)$ & $<0.001$ \\
\hline LDL-C (mmol/L) $)^{\mathrm{a}}$ & $2.72(2.27-3.26)$ & $2.70(2.26-3.23)$ & $2.85(2.44-3.42)$ & 0.015 \\
\hline $\mathrm{FBG}(\mathrm{mmol} / \mathrm{L})^{\mathrm{a}}$ & $4.83(4.20-5.76)$ & $4.73(4.15-5.55)$ & $5.74(4.56-6.77)$ & $<0.001$ \\
\hline Immunoglobulin A (mg/dL) & $336(253-430)$ & $336(252-429)$ & $338(256-436)$ & 0.367 \\
\hline Immunoglobulin G (mg/dL) ${ }^{\mathrm{a}}$ & $1580(1360-1830)$ & $1590(1360-1853)$ & $1540(1380-1760)$ & 0.184 \\
\hline Immunoglobulin M (mg/dL) ${ }^{a}$ & $101(71-140)$ & $102(71-141)$ & $97(71-135)$ & 0.320 \\
\hline Immunoglobulin $\mathrm{E}(\mathrm{IU} / \mathrm{dL})^{\mathrm{a}}$ & $2.96(0.88-8.77)$ & $3.16(0.97-9.48)$ & $1.93(0.64-5.69)$ & 0.002 \\
\hline Immunoglobulin kappa (mg/dL) ${ }^{\mathrm{a}}$ & $414(355-484)$ & $417(355-490)$ & $407(355-458)$ & 0.096 \\
\hline Immunoglobulin lambda (mg/dL) & $209(177-251)$ & $210(178-252)$ & $205(173-242)$ & 0.280 \\
\hline Complement C3 (mg/dL) ${ }^{\mathrm{a}}$ & $97(85-111)$ & $96(84-109)$ & $104(92-122)$ & $<0.001$ \\
\hline Complement C4 (mg/dL) ${ }^{\mathrm{a}}$ & $23(18-28)$ & $23(18-27)$ & $24(20-29)$ & 0.085 \\
\hline
\end{tabular}

MetS metabolic syndrome, WC waist circumference, SBP systolic blood pressure, DBP diastolic blood pressure, $H D L-C$ high-density lipoprotein cholesterol, $L D L-C$ lowdensity lipoprotein cholesterol, $F B G$ fasting blood glucose

a Described as median (interquartile range), and then compared with a Mann-Whitney U test

b Described as number (percentage), and then compared with a Chi square test 


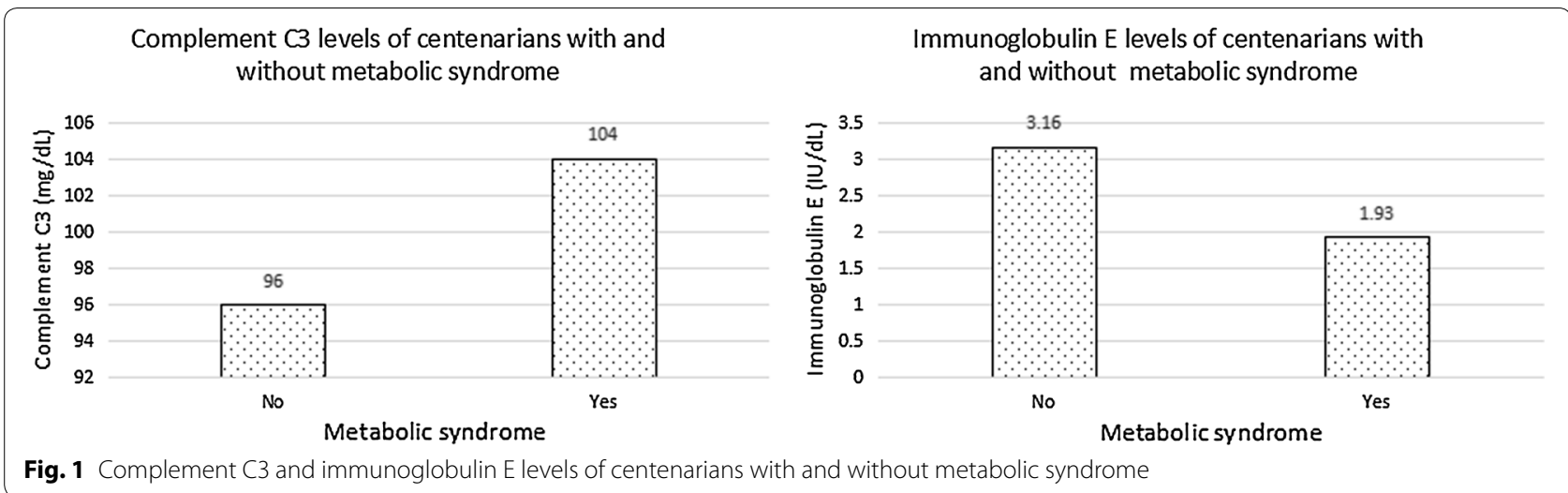

Table 2 Associations of immunological factors with metabolic syndrome

\begin{tabular}{|c|c|c|c|c|c|c|}
\hline Features & OR & $95 \% \mathrm{Cl}$ & $P$ value & OR & $95 \% \mathrm{Cl}$ & $P$ value \\
\hline \multicolumn{7}{|l|}{ Metabolic syndrome } \\
\hline Immunoglobulin A (mg/dL) & 1.000 & $0.999-1.001$ & 0.796 & 1.000 & $0.999-1.001$ & 0.741 \\
\hline Immunoglobulin G (mg/dL) & 1.000 & $0.999-1.000$ & 0.076 & 1.000 & $0.999-1.000$ & 0.120 \\
\hline Immunoglobulin M (mg/dL) & 1.000 & $0.997-1.003$ & 0.877 & 0.999 & $0.996-1.002$ & 0.648 \\
\hline Immunoglobulin E (IU/dL) & 0.980 & $0.964-0.996$ & 0.016 & 0.981 & $0.966-0.997$ & 0.021 \\
\hline Immunoglobulin kappa (mg/dL) & 0.998 & $0.997-1.000$ & 0.066 & 0.999 & $0.997-1.000$ & 0.104 \\
\hline Immunoglobulin lambda (mg/dL) & 0.998 & $0.995-1.001$ & 0.315 & 0.999 & $0.996-1.002$ & 0.356 \\
\hline Complement C3 (mg/dL) & 1.022 & $1.013-1.030$ & $<0.001$ & 1.020 & $1.012-1.029$ & $<0.001$ \\
\hline Complement C4 (mg/dL) & 1.017 & $0.997-1.038$ & 0.097 & 1.016 & $0.996-1.036$ & 0.128 \\
\hline
\end{tabular}

OR odds ratio, $95 \%$ Cl $95 \%$ confidence interval

abdominal obesity was significantly associated with immunoglobulin E [crude OR (95\% CI) 0.987 (0.9760.997); adjusted OR (95\% CI) 0.987 (0.977-0.998); $\mathrm{P}<0.05$ for all] and complement C3 levels [crude OR $(95 \% \mathrm{CI})$ 1.018 (1.011-1.026); adjusted OR (95\% CI) 1.018 (1.0101.025); $\mathrm{P}<0.05$ for all]. Additionally, dyslipidemia [crude OR (95\% CI) 1.034 (1.026-1.042); adjusted OR (95\% CI) 1.034 (1.026-1.042); $\mathrm{P}<0.05$ for all] and abnormal blood lipids [crude OR (95\% CI) 1.021 (1.014-1.028); adjusted OR (95\% CI) 1.020 (1.013-1.027); $\mathrm{P}<0.05$ for all] were significantly associated with complement $\mathrm{C} 3$ levels.

\section{Discussion}

As the first study in the world, the present study demonstrates that MetS has significant associations with immunoglobulin E and complement C3 levels, and abdominal obesity is significantly associated with immunoglobulin $\mathrm{E}$ and complement $\mathrm{C} 3$ levels in Chinese centenarians.

MetS is a practical method for identifying individuals with a high risk of cardiovascular disorders and all-cause mortality [24, 25]. MetS has complex pathophysiology, and its relationship with immunological function has been only partially elucidated [5]. Previous studies have found that immunological factors may be related to MetS
[8, 9]. However, other studies have not observed significant associations of these immunological factors with MetS $[3,10]$. Because previous studies are limited and their results are controversial, further epidemiological investigations are needed to evaluate these associations. To our knowledge, there has been scarce study assessing these associations in the elderly, and nearly no study, particularly large-scale study, investigating these associations in the centenarians $[8,9]$. It is essential to make a comparison of these associations between different age-group populations. With a considerable population-based centenarian samples, the present study confirms that MetS have significant associations with immunoglobulin $\mathrm{E}$ and complement C3 levels in Chinese centenarians.

The complement system plays an important role in innate and adaptive immunological mechanisms. Complement C3 is a major protein of the complement pathways [26]. Complement C3 levels have been correlated with MetS in previous studies [27, 28]. There may be an increase in complement C3 levels in relation to MetS in the elderly $[29,30]$. However, another study has not observed significant associations between MetS and complement C3 levels [10]. The present study finds that MetS is significantly associated with complement C3 
Table 3 Associations of immunological factors with characteristic elements of metabolic syndrome

\begin{tabular}{|c|c|c|c|c|c|c|}
\hline Features & OR & $95 \% \mathrm{Cl}$ & P value & OR & $95 \% \mathrm{Cl}$ & $P$ value \\
\hline \multicolumn{7}{|l|}{ Abdominal obesity } \\
\hline Immunoglobulin E (IU/dL) & 0.987 & $0.976-0.997$ & 0.015 & 0.987 & $0.977-0.998$ & 0.019 \\
\hline Complement C3 (mg/dL) & 1.018 & $1.011-1.026$ & $<0.001$ & 1.018 & $1.010-1.025$ & $<0.001$ \\
\hline \multicolumn{7}{|l|}{ Hypertension } \\
\hline Immunoglobulin E (IU/dL) & 0.996 & $0.991-1.001$ & 0.098 & 0.996 & $0.991-1.001$ & 0.099 \\
\hline Complement C3 (mg/dL) & 1.007 & $1.000-1.014$ & 0.056 & 1.006 & $0.999-1.014$ & 0.084 \\
\hline \multicolumn{7}{|l|}{ High blood pressure } \\
\hline Immunoglobulin E (IU/dL) & 0.995 & $0.990-1.001$ & 0.086 & 0.995 & $0.990-1.001$ & 0.086 \\
\hline Complement C3 (mg/dL) & 1.008 & $1.000-1.017$ & 0.060 & 1.008 & $0.999-1.017$ & 0.074 \\
\hline \multicolumn{7}{|l|}{ Dyslipidemia } \\
\hline Immunoglobulin E (IU/dL) & 0.995 & $0.989-1.001$ & 0.132 & 0.995 & $0.989-1.002$ & 0.137 \\
\hline Complement C3 (mg/dL) & 1.034 & $1.026-1.042$ & $<0.001$ & 1.034 & $1.026-1.042$ & $<0.001$ \\
\hline \multicolumn{7}{|l|}{ Abnormal blood lipids } \\
\hline Immunoglobulin E (IU/dL) & 0.998 & $0.992-1.003$ & 0.411 & 0.998 & $0.992-1.003$ & 0.433 \\
\hline Complement C3 (mg/dL) & 1.021 & $1.014-1.028$ & $<0.001$ & 1.020 & $1.013-1.027$ & $<0.001$ \\
\hline \multicolumn{7}{|l|}{ Diabetes mellitus } \\
\hline Immunoglobulin E (IU/dL) & 1.000 & $0.992-1.008$ & 0.922 & 1.000 & $0.992-1.008$ & 0.915 \\
\hline Complement C3 (mg/dL) & 0.994 & $0.984-1.004$ & 0.262 & 0.994 & $0.984-1.004$ & 0.254 \\
\hline \multicolumn{7}{|l|}{ High blood glucose } \\
\hline Immunoglobulin E (IU/dL) & 0.997 & $0.991-1.004$ & 0.376 & 0.997 & $0.991-1.003$ & 0.373 \\
\hline Complement C3 (mg/dL) & 0.997 & $0.990-1.004$ & 0.387 & 0.997 & $0.990-1.004$ & 0.387 \\
\hline
\end{tabular}

OR odds ratio, 95\% Cl 95\% confidence interval

levels in Chinese centenarians. Although the mechanism responsible for this association has not yet been known, there are some possible explanations. Complement C3 is synthesized in the liver [31]. The cytokines that stimulate hepatic production of complement $\mathrm{C} 3$ are mainly secreted by excess adipose tissue [30]. Complement $\mathrm{C} 3$ is also synthesized by activated adipocytes and macrophages, and behaves as both a cytokine and an adipokine [32]. These cytokines may promote insulin resistance by increasing the phosphorylation and proteosomal degradation of insulin receptor substrates or by affecting the insulin receptor-substrate interaction [33]. As the main degraded product and active fragment of C3, acylation stimulating protein (ASP, C3a desArg) has insulinlike properties and favors lipid synthesis in adipocytes [34]. Thus, in the same way that increased insulin levels may be induced by the presence of insulin resistance, an ASP resistance may cause an increased ASP precursor levels (C3) [35].

Immunoglobulin E levels are often associated with immunological function and allergic response, and has been reported to have significant associations with cardiovascular disorders [7]. Abnormal immunological function may contribute to the development of MetS [6]. Previous studies have proposed that among young, middle-aged and older adults, immunoglobulin E levels are significantly higher in individuals with MetS than those without MetS [9]. However, another study has not found the associations between MetS and immunoglobulin $\mathrm{E}$ levels [3]. Furthermore, there is a lack of evidence to show the associations between MetS and immunoglobulin E levels in the centenarians, particularly in China. The present study finds significant association between MetS and immunoglobulin E levels in Chinese centenarians. The relationships between MetS and immunoglobulin E levels are complicated, and the specific mechanism remains unclear. In experimental animals, allergic response and immunoglobulin $\mathrm{E}$ are suppressed by insulin resistance [36]. Immunoglobulin E not only induces the activation and apoptosis of endothelial cells, mast cells and macrophages, but also affects the expression and function of cell-related cytokines [37]. These cells and cytokines have been shown to be very significant in the development of obesity and MetS [38]. Thus, immunoglobulin E may be involved in MetS by directly or indirectly interacting with these cells and cytokines [36].

Previous studies have shown that complement C3 and immunoglobulin $\mathrm{E}$ levels have strong associations with insulin resistance and abdominal obesity in the young and middle-aged populations [39-42]. Complement C3 and immunoglobulin E levels have been strongly associated with insulin resistance and abdominal obesity in the 
elderly [30]. The present study shows abdominal obesity as an associated characteristic element of MetS with immunoglobulin E levels in Chinese centenarians. Moreover, the present study illustrates that abdominal obesity is a characteristic element of MetS associated with complement C3 levels in Chinese centenarians. Of all the characteristic elements of MetS, WC and abdominal obesity have been considered to be the most strongly associated with insulin resistance and MetS [30]. Abdominal adipose may be an immunological organ and result in insulin resistance and MetS [43, 44]. High expression of $\mathrm{C} 3$ is correlated with visceral adipose and abdominal obesity [38]. ASP (C3a-desArg) can stimulate lipogenesis in adipose cells. Thus, complement $\mathrm{C} 3$ may aggravate abdominal obesity and affect lipid metabolism, further contributing to the development of MetS $[45,46]$. Adipose tissue may produce complement $\mathrm{C} 3$ and trigger an immunological response [43].

The present study had one limitation. It had no interpretation of these associations between immunological factors and MetS in form of external factors, such as dietary and environmental factors, or endogenous factors, such as hormones or adipokines.

\section{Conclusions}

The present study provides epidemiological evidence that MetS has significant associations with immunoglobulin $\mathrm{E}$ and complement $\mathrm{C} 3$ levels in Chinese centenarians. Moreover, the present study demonstrates that abdominal obesity is significantly associated with immunoglobulin $\mathrm{E}$ and complement $\mathrm{C} 3$ levels in Chinese centenarians.

\section{Authors' contributions}

FS, YY, LFQ, ZF, ZY, LFX: contributed to the study design, performed the data collection and analyses, and drafted the paper. All authors read and approved the final manuscript.

\footnotetext{
Author details

${ }^{1}$ Department of Geriatric Cardiology, Chinese People's Liberation Army General Hospital, Beijing, China. ${ }^{2}$ Department of Cardiology and Hainan Branch, Chinese People's Liberation Army General Hospital, Beijing, China. ${ }^{3}$ Institute of Geriatrics, Chinese People's Liberation Army General Hospital, Beijing, China ${ }^{4}$ Beijing Key Laboratory of Aging and Geriatrics, Chinese People's Liberation Army General Hospital, Beijing, China. ${ }^{5}$ Department of Ultrasound, Hainan Branch of Chinese People's Liberation Army General Hospital, Sanya, China. ${ }^{6}$ Central Laboratory, Hainan Branch of Chinese People's Liberation Army General Hospital, Sanya, China.
}

\section{Acknowledgements}

We appreciate all the staff of $\mathrm{CHCCS}$ for their continued cooperation and contribution in field work.

\section{Competing interests}

The authors declare that they have no competing interests.

\section{Availability of data and materials}

In attempt to preserve the privacy of individuals, clinical data will not be shared; the data can be available from authors upon request.
Consent for publication Not applicable.

\section{Ethics approval and consent to participate}

The current study received the approval from Ethics Committee of Hainan branch of Chinese People's Liberation Army General Hospital (Sanya, Hainan;

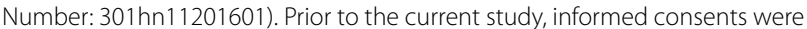
required from all participants.

\section{Funding}

This work was supported by Grants from Key Research and Development Program of Hainan (ZDYF2016135, ZDYF2016169 and ZDYF2017095), Sanya Medical and Health Science and Technology Innovation Project (2016YW21), and Clinical Scientific Research Supporting Fund of Chinese People's Liberation Army General Hospital (2017FC-CXYY-3009). The sponsors had no role in the design, conduct, interpretation, review, approval or control of this article.

\section{Publisher's Note}

Springer Nature remains neutral with regard to jurisdictional claims in published maps and institutional affiliations.

Received: 30 August 2018 Accepted: 13 November 2018

Published online: 19 November 2018

\section{References}

1. Aguilar M, Bhuket T, Torres S, Liu B, Wong RJ. Prevalence of the metabolic syndrome in the United States, 2003-2012. JAMA. 2015;313(19):1973-4.

2. Eckel RH, Alberti KG, Grundy SM, Zimmet PZ. The metabolic syndrome. Lancet. 2010;375(9710):181-3.

3. Liu Z, Tang Q, Wen J, Tang Y, Huang D, Huang Y, Xie J, Luo Y, Liang M, Wu C, Lu Z, Tan A, Gao Y, Wang Q, Jiang Y, Yao Z, Lin X, Zhang H, Mo Z, Yang $X$. Elevated serum complement factors 3 and 4 are strong inflammatory markers of the metabolic syndrome development: a longitudinal cohort study. Sci Rep. 2016;6:18713.

4. Kastorini CM, Panagiotakos DB, Georgousopoulou EN, Laskaris A, Skourlis N, Zana A, Chatzinikolaou C, Chrysohoou C, Puddu PE, Tousoulis D, Stefanadis C, Pitsavos C, ATTICA Study Group. Metabolic syndrome and 10-year cardiovascular disease incidence: the ATTICA study. Nutr Metab Cardiovasc Dis. 2016;26(3):223-31.

5. Kaur J. A comprehensive review on metabolic syndrome. Cardiol Res Pract. 2014;2014:943162.

6. Hotamisligil GS. Inflammation and metabolic disorders. Nature. 2006:444(7121):860-7.

7. Kovanen PT, Manttari M, Palosuo T, Manninen V, Aho K. Prediction of myocardial infarction in dyslipidemic men by elevated levels of immunoglobulin classes A, E, and G, but not M. Arch Intern Med. 1998;158(13):1434-9.

8. Phillips CM, Kesse-Guyot E, Ahluwalia N, McManus R, Hercberg S, Lairon D, Planells R, Roche HM. Dietary fat, abdominal obesity and smoking modulate the relationship between plasma complement component 3 concentrations and metabolic syndrome risk. Atherosclerosis. 2012;220(2):513-9.

9. Wang Z, Shen XH, Feng WM, Qiu W. Mast cell specific immunological biomarkers and metabolic syndrome among middle-aged and older Chinese adults. Endocr J. 2017;64(3):245-53.

10. Wamba PC, Mi J, Zhao XY, Zhang MX, Wen Y, Cheng H, Hou DQ, Cianflone K. Acylation stimulating protein but not complement $\mathrm{C} 3$ associates with metabolic syndrome components in Chinese children and adolescents. Eur J Endocrinol. 2008;159(6):781-90.

11. Ford ES, Giles WH, DietzWH. Prevalence of the metabolic syndrome among US adults: findings from the third National Health and Nutrition Examination Survey. JAMA. 2002;287(3):356-9.

12. Evert J, Lawler E, Bogan H, Perls T. Morbidity profiles of centenarians: survivors, delayers, and escapers. J Gerontol A Biol Sci Med Sci. 2003;58(3):232-7.

13. Ismail K, Nussbaum L, Sebastiani P, Andersen S, Perls T, Barzilai N, Milman S. Compression of morbidity is observed across cohorts with exceptional longevity. J Am Geriatr Soc. 2016;64(8):1583-91. 
14. Motta M, Bennati E, Ferlito L, Malaguarnera M, Motta M, Italian Multicenter Study on Centenarians (IMUSCE). Successful aging in centenarians: myths and reality. Arch Gerontol Geriatr. 2005;40(3):241-51.

15. Jopp DS, Park MK, Lehrfeld J, Paggi ME. Physical, cognitive, social and mental health in near-centenarians and centenarians living in New York City: findings from the Fordham Centenarian Study. BMC Geriatr. 2016;16:1.

16. He Y, Zhao Y, Yao Y, Yang S, Li J, Liu M, Chen X, Wang J, Zhu Q, Li X, Zhang F, Luan F. Cohort profile: the China Hainan Centenarian Cohort Study (CHCCS). Int J Epidemiol. 2018;47:694-5.

17. Fu S, Yao Y, Luan F, Zhao YL. Prevalence of metabolic syndrome risk factors and their relationships with renal function in Chinese centenarians. Sci Rep. 2018;8:9863.

18. World Health Organization. Obesity: preventing and managing the global epidemic. Report of a WHO Consultation. World Health Organ Tech Rep Ser. 2000;894:1-253.

19. Alberti KG, Zimmet P, Shaw J, IDF Epidemiology Task Force Consensus Group. The metabolic syndrome: a new worldwide definition. Lancet. 2005;366(9491):1059-62.

20. Chen C, Lu FC. Department of Disease Control Ministry of Health, PR China. The guidelines for prevention and control of overweight and obesity in Chinese adults. Biomed Environ Sci. 2004;17(Suppl):1-36.

21. Committee of Cardio-Cerebro-Vascular Diseases of Gerontological Society of China; Chinese College of Cardiovascular Physicians of Chinese Medical Doctor Association. Chinese expert consensus on the diagnosis and treatment of hypertension in the elderly. Zhonghua Nei Ke Za Zhi. 2017;56(11):885-93.

22. Tong YZ, Tong NW, Teng WP, Mu YM, Zhao JJ, Shan ZY. Ning G; chinese society of endocrinology. consensus on the prevention of type 2 diabetes in Chinese adults. Chin Med J (Engl). 2017;130(5):600-6.

23. Joint Committee for Developing Chinese guidelines on Prevention and Treatment of Dyslipidemia in Adults. Chinese guidelines on prevention and treatment of dyslipidemia in adults. Zhonghua Xin Xue Guan Bing Za Zhi. 2007;35(5):390-419.

24. Vidigal Fde C, Ribeiro AQ, Babio N, Salas-Salvadó J, Bressan J. Prevalence of metabolic syndrome and pre-metabolic syndrome in health professionals: LATINMETS Brazil study. Diabetol Metab Syndr. 2015;7:6.

25. Srikanthan K, Feyh A, Visweshwar H, Shapiro J, Sodhi K. Systematic review of metabolic syndrome biomarkers: a panel for early detection, management, and risk stratification in the west virginian population. Int J Med Sci. 2016;13(1):25-38.

26. Zarkadis IK, Mastellos D, Lambris JD. Phylogenetic aspects of the complement system. Dev Comp Immunol. 2001;25(8-9):745-62.

27. Puchau B, Zulet MA, Gonzalez de Echavarri A, Navarro-Blasco I, Martinez JA. Selenium intake reduces serum C3, an early marker of metabolic syndrome manifestations, in healthy young adults. Eur J Clin Nutr. 2009;63(7):858-64.

28. Weyer C, Tataranni PA, Pratley RE. Insulin action and insulinemia are closely related to the fasting complement $C 3$, but not acylation stimulating protein concentration. Diabetes Care. 2000;23(6):779-85.

29. Muscari A, Bastagli L, Poggiopollini G, Tomassetti V, Massarelli G, Cappelletti O, Plate L, Boni P, Puddu P. Different associations of C-reactive protein, fibrinogen and C3 with traditional risk factors in middle-aged men. Int J Cardiol. 2002;83(1):63-71.

30. Muscari A, Antonelli S, Bianchi G, Cavrini G, Dapporto S, Ligabue A, Ludovico C, Magalotti D, oggiopollini G, Zoli M, Pianoro Study Group. Serum C3 is a stronger inflammatory marker of insulin resistance than C-reactive protein, leukocyte count, and erythrocyte sedimentation rate: comparison study in an elderly population. Diabetes Care. 2007;30(9):2362-8.

31. Baumann H, Gauldie J. The acute phase response. Immunol Today. 1994;15(2):74-80.

32. Choy LN, Rosen BS, Spiegelman BM. Adipsin and an endogenous pathway of complement from adipose cells. J Biol Chem. 1992;267(18):12736-41.

33. Marette A. Mediators of cytokine-induced insulin resistance in obesity and other inflammatory settings. Curr Opin Clin Nutr Metab Care. 2002;5(4):377-83.

34. Germinario R, Sniderman AD, Manuel S, Lefebvre SP, Baldo A, Cianflone K. Coordinate regulation of triacylglycerol synthesis and glucose transport by acylation-stimulating protein. Metabolism. 1993;42(5):574-80.

35. Cianflone KM, Maslowska MH, Sniderman AD. Impaired response of fibroblasts from patients with hyperapobetalipoproteinemia to acylationstimulating protein. J Clin Invest. 1990;85(3):722-30.

36. Wang Z, Zhang $H$, Shen XH, Jin KL, Ye GF, Qiu W, Qian L, Li B, Zhang YH, Shi GP. Immunoglobulin E and mast cell proteases are potential risk factors of impaired fasting glucose and impaired glucose tolerance in humans. Ann Med. 2013;45(3):220-9.

37. Wang J, Cheng X, Xiang MX, Alanne-Kinnunen M, Wang JA, Chen H, He A, Sun X, Lin Y, Tang TT, Tu X, Sjöberg S, Sukhova GK, Liao YH, Conrad DH, Yu L, Kawakami T, Kovanen PT, Libby P, Shi GP. IgE stimulates human and mouse arterial cell apoptosis and cytokine expression and promotes atherogenesis in Apoe-/- mice. J Clin Invest. 2011;121(9):3564-77.

38. Liu J, Divoux A, Sun J, Zhang J, Clément K, Glickman JN, Sukhova GK, Wolters PJ, Du J, Gorgun CZ, Doria A, Libby P, Blumberg RS, Kahn BB, Hotamisligil GS, Shi GP. Genetic deficiency and pharmacological stabilization of mast cells reduce diet-induced obesity and diabetes in mice. Nat Med. 2009;15(8):940-5.

39. Gabrielsson BG, Johansson JM, Lönn M, Jernås M, Olbers T, Peltonen M, Larsson I, Lönn L, Sjöström L, Carlsson B, Carlsson LM. High expression of complement components in omental adipose tissue in obese men. Obes Res. 2003;11(6):699-708.

40. Onat A, Hergenc G, Can G, Kaya Z, Yuksel H. Serum complement C3: a determinant of cardiometabolic risk, additive to the metabolic syndrome, in middle-aged population. Metabolism. 2010;59(5):628-34.

41. Muscari A, Massarelli G, Bastagli L, Poggiopollini G, Tomassetti V, Drago G, Martignani C, Pacilli P, Boni P, Puddu P. Relationship of serum C3 to fasting insulin, risk factors and previous ischaemic events in middle-aged men. Eur Heart J. 2000;21(13):1081-90.

42. Karkhaneh M, Qorbani M, Mohajeri-Tehrani MR, Hoseini S. Association of serum complement C3 with metabolic syndrome components in normal weight obese women. J Diabetes Metab Disord. 2017;16:49.

43. Nilsson B, Hamad OA, Ahlström H, Kullberg J, Johansson L, Lindhagen L, Haenni A, Ekdahl KN, Lind L. C3 and C4 are strongly related to adipose tissue variables and cardiovascular risk factors. Eur J Clin Invest. 2014:44(6):587-96.

44. Warnberg J, Marcos A. Low-grade inflammation and the metabolic syndrome in children and adolescents. Curr Opin Lipidol. 2008;19(1):11-5.

45. Phieler J, Garcia-Martin R, Lambris JD, Chavakis T. The role of the complement system in metabolic organs and metabolic diseases. Semin Immunol. 2013;25(1):47-53.

46. Grundy SM, Cleeman Jl, Daniels SR, Donato KA, Eckel RH, Franklin BA, Gordon DJ, Krauss RM, Savage PJ, Smith SC, Spertus JA, Costa F. Diagnosis and management of the metabolic syndrome: an American Heart Association/National Heart, Lung, and Blood Institute scientific statement: executive Summary. Circulation. 2005;112(17):2735-52. 